\title{
Orphan nuclear receptors: current perspectives
}

This article was published in the following Dove Press journal:

Journal of Receptor, Ligand and Channel Research

6 November 2013

Number of times this article has been viewed

\section{Harmit S Ranhotra \\ Orphan Nuclear Receptors Laboratory, Department of Biochemistry, St Edmund's College, Shillong, India}

Correspondence: Harmit S Ranhotra Orphan Nuclear Receptors Laboratory, Department of Biochemistry, St Edmund's College, Shillong, India Tel +9l 9615175048

Email harmitran@gmail.com

\begin{abstract}
Living organisms require a host of regulatory circuits in order to survive optimally in a given environment. Gene regulation is one of the most important mechanisms for achieving normal cellular activities and overall homeostasis. The orphan nuclear receptors (ONRs) belonging to the nuclear receptors (NR) superfamily are mediators of pleiotropic effects in multiple cell types via control of gene expression. A huge volume of studies, especially in the past two decades, has revealed the detailed structures and many functions of the ONRs. However, many biological functions governed by the ONRs through gene control remain elusive. Moreover, gene regulatory mechanisms of the ONRs are still being dissected. The ONRs can interact with other members of the NR superfamily, forming heteromeric complexes at the DNA binding sites to modulate gene transcription. Additionally, the ONRs' gene regulatory abilities are further controlled via interactions with a host of coregulators. Data from several studies have unequivocally shown that the ONRs are unique regulators of biological processes, including energy and general metabolism, immunity, growth and reproduction, cell proliferation and specialization, sensory control, and many others. Furthermore, the evidence has suggested the modulatory role played by the ONRs in the onset and progression of diseases and that targeting their activities might provide a vital tool in the treatment of various diseases. Here, the current perspective on the ONRs is being reviewed.
\end{abstract}

Keywords: orphan nuclear receptors, gene regulation, gene expression, coregulators

\section{Introduction}

Complex biological pathways and control circuits have evolved to maintain the physiologic processes and other needs of living organisms. However, gene regulation at the transcription level is the central and perhaps the most vital regulatory mechanism that exists. The regulation of gene expression is carried out in myriad ways, employing numerous complex proteins and other coregulatory factors that interact with various sequences of deoxyribonucleic acid (DNA). Transcription factors can control tissue-specific gene expression. ${ }^{1}$ Nuclear receptors (NR) represent a large family ( $>50$ members) of protein transcriptional factors endowed with robust gene regulatory activities. ${ }^{2}$ Many members of the NR superfamily respond to hormones, vitamins, and other endogenous ligands via specific binding and subsequent interaction with responsive elements in the DNA, leading to control of gene transcription. ${ }^{3}$ The NR superfamily can be sorted into groups or families. Many members of the NR superfamily were discovered by cloning approaches, and the corresponding ligands were subsequently identified. One of the groups contains the classic nuclear hormone receptors such as the glucocorticoid receptors (GRs), estrogen receptors (ERs), mineralocorticoid 
receptors (MRs), androgen receptors (ARs), and progesterone receptors (PRs). ${ }^{3-5}$ Other hormone receptors such as the thyroid receptors (TRs), vitamin D receptors (VDRs), and retinoic acid receptors (RARs), including receptors that bind various metabolites such as peroxisome proliferatoractivated receptors (PPARs), farnesoid X receptor (FXR), liver $\mathrm{X}$ receptor (LXR), pregnane $\mathrm{X}$ receptor/steroid and xenobiotic receptor (PXR/SXR), retinoid X receptor ( $R X R)$, and constitutive androstane receptor (CAR). ${ }^{6}$ The third family, the so-called orphan nuclear receptors (ONRs), whose physiological ligands are unidentified, constitutes a diverse group of transcriptional mediators. ${ }^{7-9}$ This review focuses on current perspectives of the ONRs.

\section{The prologue}

The discovery of the classic steroid, thyroid, and vitamin D hormone receptors stimulated the search for novel endogenous hormone-binding receptors with similar characteristics. ${ }^{10,11}$ These classical receptors exhibited a great degree of similar domain organization and mode of action. The high extent of structural and functional homology among the receptors led to intense investigations regarding the existence of more members of such receptors. Initially, the complimentary DNA (cDNA) library and polymerase chain reaction (PCR) screenings, and later, DNA sequence analysis, led to the discovery of many receptor members in spite of the previous non-identification of their endogenous ligands. ${ }^{12-14}$ These new groups of NRs without cognate ligands constituted a gene family and were referred to as ONRs. ${ }^{15}$ Originally, the ONRs group was large with many members, but over time, quite a number of receptors were deorphanized on account of the discovery of their respective endogenous ligands. This included members such as the RXRs, PPARs, LXRs, FXRs, CAR, and PXR which no longer belong to the ONRs family. ${ }^{16-20}$ In humans, out of a total of 48 different NR superfamily members, 24 are ONRs.

Within the ONRs, there is a high degree of diversification as many members are not functionally or evolutionarily linked. ${ }^{8}$ The majority of the ONR members in vertebrates possess the classic DNA-binding domain (DBD) and the ligand-binding domain (LBD), except the DAX-1 and SHP. ${ }^{21,22}$ The transcriptional regulation by the ONRs also exhibits distinct characteristics, as many members bind to the DNA responsive elements (conserved sequence motif of A/GGGTCA) of target genes as monomers (to extended DNA half-site sequences), some as homodimers, a few as heterodimers (ie, in association with RXRs), and one (GCNF) as an oligomeric complex. ${ }^{23-26}$ Because of the extensive diversity of the ONRs, they have vital roles in general and energy metabolism, growth, cellular proliferation, differentiation and specialization, immunity, embryogenesis, organogenesis, tissue maturation, circadian rhythm, and the onset and progression of multiple diseases. ${ }^{8,9,27-30}$

\section{The ONR family members}

As mentioned above, the ONR family incorporates a number of members that are hugely diverse. The present knowledge about the ONRs allows us to place a number of receptors under this family. Although there are reports lately suggesting finding of ligands for some of the ONR members, the explanations are not satisfactory as the physiological role of the ligands is unclear. ${ }^{8,29,31}$ Nevertheless, based on the current status of the ONRs' structure and functions, we can include quite a number of members into this family, whose cognate physiological ligands are unconfirmed. Most of the ONR members can be loosely grouped as they show some homology in amino acid sequences in certain receptor structural domains and exist as isoforms. In fact several splice variants of some of the ONR members have been detected. ${ }^{8,29}$ Of these ONR members, almost all of them have some role in the control of important biological processes, and hence, have a status equal to the classic nuclear hormone receptors. However, finding the counterpart ligands for the ONRs is being pursued in many laboratories using various approaches, including bioinformatics and it seems likely that in the future, a few ONR members may become deorphanized. The ONRs are widely distributed in rodents and humans, and the individual members and their respective isoforms are expressed in a tissue-specific fashion. Considerable knowledge has been gained about the expression of different ONRs, especially in murine models using quantitative PCR, Northern and Western analysis, in situ hybridization, and immunohistology, etc. A list of ONRs' expression in different tissues/organs in rodents/ humans is provided in Table $1 .^{8,32}$

\section{ONRs' activation}

A great majority of the members of the NR superfamily share a common, highly conserved modular domain structure. The NRs possess within the N-terminal domain (NTD), a highly divergent activation function (AF)-1 site which assists in regulating the transcriptional activity of NR members independent from ligand binding. ${ }^{33}$ Additionally, the C-terminus, including the AF-2 site of NRs, is vital in receptor-mediated gene expression control by mediating ligand and receptor interactions, coregulator binding, and also in many cases, in receptor dimerization. ${ }^{34}$ The above mentioned domains 
Table I The ONRs and their tissue distribution in mammals

\begin{tabular}{|c|c|c|c|}
\hline Receptor short name & Full name $^{\mathrm{b}}$ & $\begin{array}{l}\text { Receptor } \\
\text { nomenclature }\end{array}$ & $\begin{array}{l}\text { Tissue distribution } \\
\text { (in adults) }\end{array}$ \\
\hline $\operatorname{ERR} \alpha$ & Estrogen-related receptor alpha & NR3BI & L, K, H, G, B, L \\
\hline $\operatorname{ERR} \beta$ & Estrogen-related receptor beta & NR3B2 & $\mathrm{L}, \mathrm{K}, \mathrm{H}, \mathrm{S}, \mathrm{Sm}$ \\
\hline ERR $\gamma$ & Estrogen-related receptor gamma & NR3B3 & $\mathrm{B}, \mathrm{K}, \mathrm{Lu}, \mathrm{P}, \mathrm{T}, \mathrm{Bm}$ \\
\hline $\operatorname{ROR} \alpha$ & Retinoid-related receptor alpha & NRIFI & L, M, B, H, O, T, Si \\
\hline $\operatorname{ROR} \beta$ & Retinoid-related receptor beta & NRIF2 & Hy, E, Pt, Sp, Th \\
\hline $\mathrm{ROR} \gamma$ & Retinoid-related receptor gamma & NRIF3 & $\mathrm{Sm}, \mathrm{T}, \mathrm{H}, \mathrm{L}, \mathrm{P}, \mathrm{Th}$ \\
\hline Rev-erb $\alpha$ & Rev-erb alpha & NRIDI & $\mathrm{L}, \mathrm{H}, \mathrm{B}, \mathrm{K}, \mathrm{Sm}, \mathrm{T}$ \\
\hline Rev-erb $\beta$ & Rev-erb beta & NRID2 & $\mathrm{H}, \mathrm{B}, \mathrm{L}, \mathrm{K}, \mathrm{T}, \mathrm{Sm}$ \\
\hline SF-I & Steroidogenic factor-I & NR5AI & $\mathrm{Sp}, \mathrm{Ag}, \mathrm{Go}$ \\
\hline LRH-I & Liver receptor homologue-I & NR5A2 & L, P, Si, O, PI \\
\hline GCNF & Germ cell nuclear factor & NR6AI & $\mathrm{L}, \mathrm{K}, \mathrm{O}, \mathrm{T}$ \\
\hline NGFI-B & Nerve growth factor induced clone B & NR4AI & $\mathrm{L}, \mathrm{O}, \mathrm{T}, \mathrm{Sm}, \mathrm{Pt}, \mathrm{Lu}$ \\
\hline NURRI & Nur related factor-I & NR4A2 & $\mathrm{B}, \mathrm{L}, \mathrm{Pt}, \mathrm{Ty}, \mathrm{Os}$ \\
\hline NORI & Neuron-derived orphan receptor-I & NR4A3 & $\mathrm{B}, \mathrm{H}, \mathrm{K}, \mathrm{Pt}, \mathrm{Ag}, \mathrm{Ty}$ \\
\hline HNF-4 $\alpha$ & Hepatocyte nuclear receptor-4 alpha & NR2AI & Si, L, P, K, C \\
\hline HNF-4 $\gamma$ & Hepatocyte nuclear receptor-4 gamma & NR2A3 & $\mathrm{K}, \mathrm{Si}, \mathrm{P}, \mathrm{T}$ \\
\hline DAX-I & $\begin{array}{l}\text { Dosage-sensitive sex reversal, adrenal hypoplasia } \\
\text { critical region, on chromosome } \mathrm{X} \text {, gene I }\end{array}$ & NROBI & Ac, O, T, Pt \\
\hline SHP & Short heterodimer partner & NROB2 & L, H, P, Sp, Ag \\
\hline PNR & Photoreceptor-specific nuclear receptor & NR2E3 & Retina \\
\hline TLX & Tailless & NR2EI & $B, E, N$ \\
\hline TR2 & Testicular receptor 2 & $\mathrm{NR} 2 \mathrm{Cl}$ & L, K, T, Po \\
\hline TR4 & Testicular receptor 4 & $\mathrm{NR} 2 \mathrm{C} 2$ & $\mathrm{~B}, \mathrm{Lu}, \mathrm{T}, \mathrm{Po}, \mathrm{Ag}, \mathrm{Sp}$ \\
\hline EAR2 & ErbA-related protein & NR2F6 & $\mathrm{H}, \mathrm{K}, \mathrm{P}, \mathrm{Pl}, \mathrm{Sm}$ \\
\hline COUP-TFI & $\begin{array}{l}\text { Chicken ovalbumin upstream promoter } \\
\text { transcription factor I }\end{array}$ & $\mathrm{NR} 2 \mathrm{FI}$ & $\mathrm{B}, \mathrm{Sn}$ \\
\hline COUP-TFII & $\begin{array}{l}\text { Chicken ovalbumin upstream promoter } \\
\text { transcription factor II }\end{array}$ & $\mathrm{NR} 2 \mathrm{~F} 2$ & $\begin{array}{l}\text { Developmental } \\
(\mathrm{S}, \mathrm{K}, \mathrm{Lu}, \mathrm{P}, \mathrm{Po})\end{array}$ \\
\hline
\end{tabular}

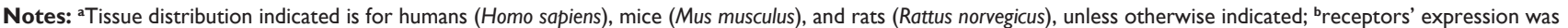
detected using, Northern blot, Western blot, qPCR, in situ hybridization, and immunohistology approaches.

Abbreviations: Sn, supraoptic nucleus; Po, prostate; N, nose; R, retina; C, colon; S, stomach; Lu, lung; Bm, bone marrow; Sm, skeletal muscle; T, testis; P, pancreas; L, liver; K, kidney; H, heart; G, gut; B, brain; U, uterus; O, ovary; Si, small intestine; Hy, hypothalamus; E, eye; Pt, pituitary; Sp, spleen; Th, thalamus; Ag, adrenal gland; Go, gonads; $\mathrm{PI}$, placenta; Os, osteoblasts; Ty, thymus; Ac, adrenal cortex; ONRs, orphan nuclear receptors.

and sites are also found in most of the ONRs, thus providing them with robust gene regulatory ability. However, in contrast to the ligand-activated NRs, the ONRs typically exhibit constitutive gene regulatory activity. In fact, in the absence of a ligand, the helix 12 motif in the ONRs AF-2 domain is prepositioned for maximal activation, thereby facilitating interactions between the ONR and cognate coregulators. ${ }^{35,36}$ The ONRs are extremely sensitive to binding and interaction with the coregulators (coactivator or corepressor). Over 200 NR coactivators and corepressors are known today, with each exhibiting differential patterns of expression, enzymatic activity, and specificity of interactions with the NR superfamily members. ${ }^{37,38}$ In fact, it is widely assumed that the coregulators themselves are acting somewhat like endogenous ligands in activating the ONRs. However, some of the ONRs still have unidentified coregulators. A list of various known coactivators and corepressors of the ONRs is provided in Table 2. Differential coregulator binding to the ONRs can directly modulate binding to specific DNA responsive elements. ${ }^{39}$ Moreover, the relative level of a coregulator in a tissue may also dictate the robustness of gene transcriptional control by the ONRs. Furthermore, it is presently unknown whether the presence of a coactivator or corepressor is sufficient to activate a particular ONR or whether the interactions between them can be modulated by signals specifically targeting the receptors. The signals could be unidentified physiological ligands or post-translational modifications (PTMs) of the ONRs stimulated by extracellular signal cascades. However, activation of the ONRs is still an intense area of investigation which nevertheless is of vital importance to basic research from the pharmacological point of view.

\section{Post-translational modifications of ONRs}

Many ligand-activated members of the NR superfamily are molecular transducers of endocrine and dietary signals, thereby 
Table 2 Various known coactivators and corepressors that interact with the different ONRs

\begin{tabular}{|c|c|c|}
\hline ONRs & Coactivators & Corepressors \\
\hline $\operatorname{ERR} \alpha$ & PNRC2, PGC-I $\alpha, P G C-I \beta, N C \circ A 3, N C \circ A 2, N C \circ A I, P N R C$ & PROXI, NCoRI, RIPI40 \\
\hline ERR $\beta$ & PNRC, NCoA3, NCoAI, NCoA2, PGC- I $\alpha$ & RIPI40 \\
\hline ERR $\gamma$ & PGC- $\mid \alpha$, PGC-I $\beta$, PNRC2, NCoAI, TLEI & RIPI40 \\
\hline \multirow[t]{2}{*}{$\mathrm{ROR} \alpha$} & NCoAI, NCoA2, PPARBP, p300, PGC-I $\alpha$, CBP & NCoRI, NCoR2, HR, FOXP3 \\
\hline & & NRIP2, HR, FOXP3 \\
\hline ROR $\beta$ & NCoAI, NCoA2, p300, PGC-I $\alpha$, CBP & HR, FOXP3, NCoRI \\
\hline $\mathrm{ROR} \gamma$ & NCoAI, NCoA2, p300, PGC-I $\alpha$, CBP & NCoRI, CId, HDAC3, \\
\hline Rev-erb $\alpha$ & NCoA5 & NCoRI, NCoA5 \\
\hline Rev-erb $\beta$ & $\mathrm{NCoA} 5$ & NCoR2, DPI03 \\
\hline SF-I & CBP, NCoAI, NCoA2, EDFI, PNRC2 & PROXI \\
\hline LRH-I & NCoAI, NCoA3, p300, NCoA62, EDFI & NCoRI, NCoR2 \\
\hline GCNF & RAP80 & - \\
\hline NGFI-B & NCoAI, NCoA2, NCoA3, p300, PPARBP, KAP-I & - \\
\hline NURRI & PGC-I $\alpha$ & - \\
\hline NORI & SIX3, PPARBP, p300, NCoA2, PCAF & NCoR2 \\
\hline HNF-4 $\alpha$ & NCoAI, NCoA2, CBP, PGC-I $\alpha, P G C-I \beta$ & - \\
\hline HNF-4 $\gamma$ & - & NCoRI, NORR2, COPS2 \\
\hline DAX-I & - & $\mathrm{HDACI}, \mathrm{HDAC} 3, \operatorname{Sin} 3 \mathrm{~A}, \mathrm{CBP}$ \\
\hline SHP & - & $\mathrm{NCoRI}$ \\
\hline PNR & - & - \\
\hline TLX & - & - \\
\hline TR2 & - & NRIPI, HDAC3, HDAC4 \\
\hline TR4 & - & TRA I6, TIP27 \\
\hline EAR2 & - & - \\
\hline COUP-TFI & $\mathrm{NCoAI}$ & NCoRI, NCoR2 \\
\hline \multirow[t]{2}{*}{ COUP-TFII } & BCLIIBI, NCoAI, CBP & NCoRI, NCoR2 \\
\hline & BCLIIB, SQSTMI & \\
\hline
\end{tabular}

Abbreviations: DPI03, dead box protein 103; KAP-I, KRAB domain-associated protein I; NCoA, nuclear receptor coactivator; NCoR, nuclear receptor corepressor; PROXI, prospero homeobox protein I; PNRC, proline-rich nuclear receptor coactivator; TLE-I, transducin-like enhancer protein I; P300, protein 300; HR, hairless; FOXP3, forkhead box P3; CBP, CREB-binding protein; NRIP, nuclear receptor-interacting protein; PGC-I, PPAR gamma coactivator-I; RIPI40, receptor-interacting protein I40; HDAC, histone deacetylase; RAP80, receptor-associated protein 80; EDF-I, endothelial differentiation-related factor I; PPARBP, PPAR-binding protein; SIX3, six homeobox 3; PCAF, P300/CBP-associated factor; COPS2, COP9 signalosome complex subunit 2; TRAI6, TR4-associated protein I6; TIP27, TAKI-interacting protein; SQSTMI, sequestosome I; NORR2, nitric oxide reductase transcription regulator 2; BCLI IB, B-cell lymphoma/leukemia IIB; ONRs, orphan nuclear receptors.

facilitating cellular and tissue homeostasis by transforming the NRs into transcriptional modulators by on-off mechanisms. This ligand-based switching mechanism needs to be finely tuned according to organisms' needs. These critical adjustments of NR transcriptional activity are brought about by PTMs, which represent a major regulatory mechanism. ${ }^{40,41}$ However, with regard to the ONRs, the PTMs may be a vital, and perhaps the sole, regulatory mechanism. The PTMs of the classic NR members include phosphorylation, acetylation, sumoylation, methylation, myristoylation, nitration, ADPribosylation, and isoprenylation. These PTMs can be further divided into two groups: firstly, PTMs that function by either the addition or removal of functional chemical groups (ie, phosphate, acetyl) on specific amino acid residues of target proteins, or secondly, involving addition of other proteins or polypeptides (eg, sumoylation and ubiquitination) and regulated degradation (proteolysis). ${ }^{41}$

The role of PTMs in ONR activity is just beginning to be understood. The ONR retinoid-related orphan receptor alpha1
(ROR $\alpha 1$; NR1F1) is constitutively active; however, its regulation is not well known. Protein kinase C (PKC) is a major cellular kinase participating in signal transduction. $\mathrm{ROR} \alpha 1$ in cortical neurons and COS-7 cells when treated with different effectors acting on PKC activity rapidly phosphorylates and inhibits ROR $\alpha 1$ activity. ${ }^{42}$ The pro-apoptotic ONR member Nur77 (NR4A1) cellular localization is controlled by its phosphorylation by the activated Jun N-terminal kinase (JNK). ${ }^{43}$ The inhibition of JNK activity by a JNK inhibitor suppresses Nur77 nuclear export and apoptosis while the activation of JNK by activators such as anisomycin and MAPK kinase kinase-1 (MEKK1), phosphorylated Nur77 and induced its nuclear export. ${ }^{43}$ Hence, the subcellular localization of Nur77 is determined by its phosphorylation status, which regulates its apoptotic activity. The estrogen-related receptor alpha $(E R R \alpha)$ is a well-known ONR with a robust role in energy homeostasis and metabolism. ${ }^{29,44}$ Proteasomal degradation of nuclear ERR $\alpha$ has been recently ascribed to control its gene regulatory activity. ${ }^{45}$ Cell treatment studies 
have shown that a biarylpyrazole compound AM251 directly binds and destabilizes the nuclear ERR $\alpha$, but not ERR $\gamma$ by proteasome-mediated degradation of the receptor involving the SUMO and protein kinase $\mathrm{C}$ pathway.

Parkin is a protein and is a component of a multiprotein E3 ubiquitin ligase of the larger ubiquitin-proteasome system that mediates the targeting of proteins for degradation. ${ }^{46}$ Parkin regulates oxidative stress by attenuating the expression of mitochondrial monoamine oxidase (MAO) A and B that mediate the oxidative deamination of dopamine. Interestingly, MAO genes are upregulated by the ERRs. New findings have shown that parkin influences ERR activities by causing ubiquitination and degradation of ERR $\alpha, \beta$, and $\gamma$, and thus reduces MAO's expression. ${ }^{47}$ These novel mechanisms of control of ERR activity exist endogenously, which perhaps provide an efficacious way of regulating mitochondrial physiology towards maintaining energy homeostasis. The testicular receptor 4 (TR4), an ONR, controls growth, development, and metabolism by regulating specific target genes. The gene regulatory activity of TR4 in the absence of the cognate ligand has been shown to be controlled by the androgen receptor (AR) coactivator, ARA55, which might function as a corepressor to inhibit TR4-mediated gene transactivation. ${ }^{48}$ Mechanistically, ARA55 might increase TR4 acetylation at the conserved sites of lysine 175 and lysine 176 in the DBD via recruiting proteins with histone acetyl transferase activity. This increased acetylation might decrease TR4 DNA-binding activity, leading to reduced TR4-mediated gene transactivation.

The ONR subfamily members, the steroidogenic factor 1 (SF-1) and liver receptor homologue 1 (LRH-1) are repressed via post-translational SUMO modification at the conserved lysine within the hinge domain (Figure 1). ${ }^{49}$
SUMO-mediated repression involves direct interaction of the DEAD-box protein DP103 with the sumoylated SF-1. Moreover, a study in rat granulosa cells has demonstrated that the coexpression of SUMO-1 targets LRH-1 by sumoylation at five lysine residues to the dot-like transcriptionally inactive nuclear bodies. ${ }^{50}$ Thus, sumoylation in general appears to be a robust regulator of ONR activity. Together, these results show that PTMs of different ONRs may lead to differential receptor transactivation activity, thus affecting a number of biological processes, probably in the absence of specific regulatory ligands. However, little is presently known about the in vivo contribution of PTMs of ONRs towards their control of gene expression activities. Moreover PTMs of a number of classic NRs such as the GR, ER $\alpha$, and AR, including $\operatorname{PPAR} \gamma$, markedly control their receptor functions, including facilitating the onset and progression of diseases such as cancer, diabetes, and obesity. ${ }^{41}$ Therefore it seems likely that the ONRs activities are governed by the various PTMs. It can be visualized that together with PTMs, other unknown cellular regulatory events might regulate the transcriptional activities of the ONRs.

\section{ONRs and biological functions}

The biological processes regulated by the ONRs are quite varied and vast on account of their diversity. As a result, it is difficult to summarize each of their roles. Nevertheless, functions revealed recently by select ONRs shall be discussed here. Most of the roles of the ONRs have been known by the use of various molecular approaches and through the generation of ONR-specific knockout mice, although the bulk of their roles remain to be determined. The ERR member ERR $\alpha$ has recently been shown to control osteoblastogenesis. Experimental results from multiple systems demonstrated that

A

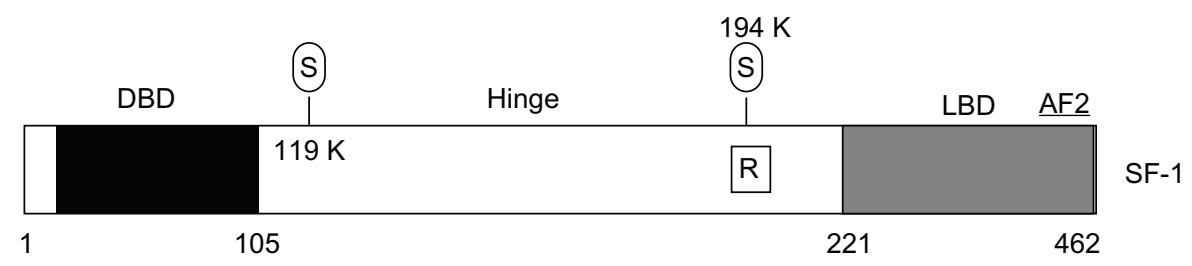

B

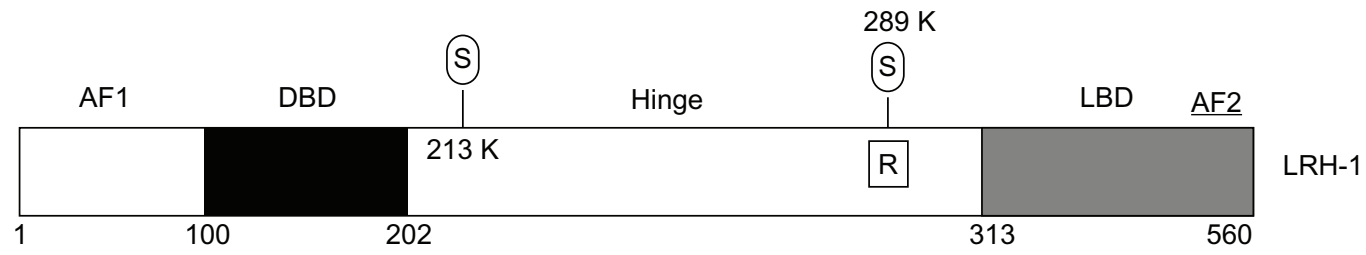

Figure I A schematic domain structure of mouse (A) SF-I and (B) LRH-I protein showing the post-translational sumoylation (S) sites and the repression (R) site. Sumoylation of SF-I and LRH-I occurs at the conserved lysine $(\mathrm{K})$ residues indicated with the respective number.

Abbreviations: LBD, ligand-binding domain; DBD, DNA-binding domain; LRH-I, liver receptor homologue I; SF-I, steroidogenic factor I. 
ERR $\alpha$ in conjunction with PGC-1 $\alpha$ modulates Wnt signaling, leading to osteoblast differentiation. ${ }^{51}$ In thyroid tumors, cellular metabolic adaptation is brought about by upregulation of ERR $\alpha$, thereby regulating oxidative metabolism and their proliferative status. One of the mechanisms by which this can be controlled was recently demonstrated, wherein ERR $\alpha$ upregulation led to a concomitant decrease in lactate dehydrogenase (LDH) A and B isoforms activity in human thyroid tumor cell lines, perhaps helping tumor growth via a pathway other than the Warburg effect. ${ }^{52}$ PGC- $1 \alpha$ is a master regulator and has a central role in oxidative metabolism. A new report has shown that $P G C-1 \alpha$ gene expression in primary cardiomyocytes is under the control of ERR $\alpha$ as its promoter contains functional ERR-responsive element (ERRE). ${ }^{53}$ Furthermore, ChIP analysis has shown that overexpression of ERR $\alpha$ increases its occupancy on the PGC- $1 \alpha$ promoter ERRE and upregulates its expression, and together, they have a robust control on cardiac energy metabolism. ERR $\gamma$ has an important role in metabolism and was recently shown to regulate hepatic gluconeogenesis by acting as a downstream mediator of glucagon action. ${ }^{54}$ In the study, overexpression of ERR $\gamma$ induced phosphoenolpyruvate carboxykinase 1 $(P c k 1)$ and glucose-6-phosphatase $(G 6 P C)$ gene expression and glucose synthesis in primary hepatocytes, whereas interference of ERR $\gamma$ expression decreased gluconeogenic gene expression. ChIP analysis showed ERR $\gamma$ bound to the Pckl promoter ERRE, demonstrating that ERR $\gamma$ directly controls Pckl transcription.

The retinoid-related orphan receptor alpha $(\operatorname{ROR} \alpha)$ controls development and growth in lipid and glucose metabolism in major metabolic tissues and organs, including participation in circadian rhythm (CR). ${ }^{55-57}$ Moreover, ROR $\gamma$ has been reported to regulate circadian cycle by controlling the expression of clock genes Cry1, Bmall, E4bp4, Rev$E r b \alpha$, and Per2, and is a player in the regulation of glucose/ lipid homeostasis and insulin sensitivity. ${ }^{58,59}$ The ONR Reverb $\alpha$ in conjunction with its coreceptor, the photoreceptorspecific nuclear receptor (PNR), regulates transcriptional networks by controlling numerous target genes (such as Nr2c1, Rgr, Rarres 2, Pde8a, and Nuprl) as expression is critical for photoreceptor development and function in the retina. ${ }^{60} \mathrm{~A}$ new report by Cho et al suggests vital roles for Rev-erb $\alpha$ and Rev-erb $\beta$ in controlling the circadian cycle and metabolism as a result of studies in double-knockout mice. ${ }^{61}$ Steroidogenic factor 1 (SF-1) is a known master regulator of steroidogenesis. Recently, SF-1 another ONR, was identified to regulate human glutathione S-transferase A family genes, a superfamily of detoxification enzymes using genome-wide promoter tiling array and DNA microarray with a crucial role in steroidogenesis. ${ }^{62}$ On the other hand, the ONRs liver receptor homologue 1 (LRH-1) and hepatocyte nuclear factor alpha (HNF4 $\alpha$ ) have been shown as important transcriptional regulators of cholesterol $7 \alpha$-hydroxylase (Cyp7a1) expression in vivo. ${ }^{63}$ Nur77 (also known as TR3) is another ONR where a new study has demonstrated that its signaling pathway regulates endoplasmic reticulum stress and induces apoptosis of hepatoma cells through its interaction with a translocon-associated protein subunit $\gamma$ (TRAP $\gamma)$ as a binding cofactor. ${ }^{64}$

The chicken ovalbumin upstream promoter transcription factor 1 (COUP-TF1) is an important ONR and has been shown to modulate the expression of kallikrein-binding protein (KBP, a component of the kallikrein-kinin system that mediates vasodilation). ${ }^{65}$ The other member, COUP-TFII has been identified to regulate the expression of many genes in the cell cycle pathway and Notch signaling pathway, including the control of pancreatic $\beta$-cell mass through glucagonlike peptide 1 (GLP-1)- $\beta$-catenin signaling pathways. ${ }^{66,67}$ A recent report strongly suggests a critical role for the ONR dosage-sensitive sex reversal adrenal hypoplasia congenital critical region on the X chromosome, gene 1 (DAX-1) in the insulin-mediated steroidogenesis in testicular Leydig cells, and also in human adrenal gland function. ${ }^{68,69}$ Investigation by Yuk et al showed that the ONR short heterodimer protein (SHP) appears to be a negative regulator of Toll-like receptor (TLR)-triggered inflammatory responses, with another study showing that SHP potentially modulates the innate immune signaling pathway through the mitochondrial uncoupling protein $2{ }^{70,71}$ The PNR as mentioned above is an important ONR that along with Rev-erb $\alpha$ regulates transcriptional networks of various target genes involved in photoreceptor development in the retina. ${ }^{60}$ Also, PNR regulates ER $\alpha$ expression via direct binding to the Esrl gene promoter in breast cancer cells, and is required for the cellular activity of ER $\alpha$ in ER-positive breast cancer cells. ${ }^{72}$ The ONR TLX (tailless homologue), also known as NR2E1, controls the proliferation of adult neural stem cells and its upregulation promotes brain tumor formation; a recent report suggests that it also regulates gliomagenesis (development of primary brain tumors). ${ }^{73}$ Moreover, TLX also controls angiogenesis through interaction with the von Hippel-Lindau protein. ${ }^{74}$ The ONRs have a very broad spectra of biological roles and it is beyond the scope of this review to exhaustively discuss them. In future, finding their roles would certainly have a huge impact on biomedical research and on human health and disease. 


\section{ONRs, molecular clocks, and circadian rhythm}

CR is comprised of physical, mental, and behavioral changes that follow a roughly 24-hour cycle, responding primarily to light and darkness in an organism's environment. ${ }^{75}$ Our $\mathrm{CR}$ is controlled by biological (molecular) clocks which are a group of interacting cellular molecules (mainly proteins) distributed throughout the body. A master clock (group of nerve cells in the brain suprachiasmatic nucleus) coordinates all the body clocks so that they are synchronized. Many of the ONR members have been directly linked as a component of molecular clocks in order to regulate CR. ${ }^{76,77}$ ERR $\alpha$ appears to control clock function in peripheral tissues. ERR $\alpha$ has been linked to be a regulator of the molecular clock in the liver. ${ }^{78}$ An array of core clock genes whose promoters are the direct target of ERR $\alpha$ is known, which include Bmall, Clock, Cry1, Per2, Rev-erb $\alpha$, and Rev-erb $\beta .^{78}$ Moreover, normal expression of ERR $\alpha$ is necessary for the maintenance of $\mathrm{CR}$ in the expression of these core clock genes in the liver. $\mathrm{CR}$ and metabolism must be tightly integrated to maintain homeostasis in organisms. Components of the molecular clock can directly control some metabolic genes. ERR $\alpha$ has been shown to be a direct regulator of the molecular clock, thereby exerting robust control over the cellular metabolic networks. ${ }^{79}$ Thus, ERR $\alpha$ is a robust transcriptional mediator linking metabolism with $\mathrm{CR}$ via the molecular clock. The Rev-erbs have lately been linked to the control of the circadian clock. ${ }^{77,80}$ Rev-erb $\alpha$ and Rev-erb $\beta$ are a part of the core clock apparatus, are the major regulators of the core clock gene Bmall, and generally have repressive effects. ${ }^{81}$ Recent work has established the role of Rev-erbs in the regulation of rhythmic metabolism. ${ }^{82}$ Bugge et al showed that the loss of both hepatic Rev-erbs led to significant de-repression of clock genes and that both the subtypes' activities are wellcoordinated to guard against major perturbations in metabolic and circadian physiology. ${ }^{83}$

The ROR $\alpha$ is a crucial member of the core clock machinery and regulates multiple metabolic pathways. It likely coordinates the translation of circadian signals into metabolic events. In mammals, the circadian clock is regulated at the cellular level by a transcriptional/translational feedback loop. BMAL1 is one of the positive transcriptional regulators and is an integral factor of the molecular clock. BMAL1 in association with another gene regulator 'clock', or NPAS2, heterodimerizes to upregulate the cyclic expression of core clock genes and mediators of the molecular clock called clock-controlled genes. ${ }^{84,85}$ The circadian expression of BMAL1 is influenced by ROR $\alpha$, as the Bmall promoter contains ROR response element (RORE). However, NPAS2, the other obligate partner of BMAL1, was also demonstrated to be a direct target of ROR $\alpha$ as its promoter contains two functional ROREs. The transcription of NPAS2 is thus controlled by ROR $\alpha$, which facilitates the orchestrated heterodimer formation of the BMAL1/NPAS2 complex. ${ }^{85}$ A report by Poliandri et al showed that the NR repressor RIP140 is directly recruited at the RORE of the Bmall promoter that leads to interaction with ROR $\alpha$ and subsequent increase in BMAL1 expression. ${ }^{86}$ It is highly likely that the above mechanisms exist by which ROR $\alpha$ can coordinately regulate the expression of the positive arm of the $\mathrm{CR}$ feedback loop. Hence, the role of some ONRs in intrinsically regulating gene networks and an array of core clock genes seems to primarily determine the circadian clock that eventually leads to maintenance of $\mathrm{CR}$ in peripheral and central tissues in animals. Preliminary data generated by several studies have strongly suggested the pivotal role of many ONRs in the interface between molecular clock and body physiology. In fact, a significant percentage of ONR members play a direct regulatory role in the core clock mechanism and tissuespecific circadian expression profile. ${ }^{87}$ Also, quite a number of ONRs that control the core feedback loop are important metabolic sensors that suggest that the primary role of ONR signaling in $\mathrm{CR}$ is to coordinate metabolic inputs to modulate the core feedback loop. ${ }^{88}$ However, at present, we have limited knowledge on the participation of ONRs in molecular clocks and $\mathrm{CR}$; the future is certainly promising in revealing this important and complex interface.

\section{ONRs and pathogenesis}

The ONRs over the past many years have been implicated to be participants in the rise and progression of various diseases. Because of the myriad roles governed by the ONRs, deregulation of ONR activities may affect various cellular networks and pathways which may culminate in organismal complications. However, genetic evidence with respect to the involvement of the ONRs in diseases is yet to be clearly demonstrated. Nonetheless, wide ranging studies and preliminary data generated over the years convincingly raise their role in various human diseases. The NR4A subgroup, which includes Nur77 (NR4A1), Nurr1 (NR4A2), and Nor1 (NR4A3), has been suggested to be a contributor in pathogenesis. Studies indicate the roles of the NR4A members in regulating genes involved in the control of thrombosis and angiogenesis, and may contribute to vascular disease ${ }^{89}$ Initial reports indicate a potential positive role of NR4A members in the development 
of atherosclerosis. Atherosclerotic sites have increased migration and the presence of macrophages (circulating monocytes which are essential components of atherosclerosis development), where the NR4A members are highly expressed..$^{90}$ Upon receiving proinflammatory signals, the macrophage NR4A members upregulate genes taking part in inflammation, apoptosis, and cell cycle events. It seems that the control of macrophage inflammation by the NR4A receptors constitutes a vital mechanism for attracting them to the atherosclerotic site. A recent report by Zhao et al has demonstrated that the deficiency of Nor1 in circulating monocytes decreases its adhesion and atherosclerosis. ${ }^{91}$ Moreover, endothelial cells also express the NR4A receptors where they control endothelial cell proliferation during injury to the arterial wall and/or at the atherosclerotic site contributing to atherosclerosis. ${ }^{92}$

The ERRs are pivotal regulators of energy metabolism and are increasingly implicated in the onset and progression of cancers. ${ }^{9,29,44,84}$ The ERRs are highly expressed in all breast tumor subtypes and may be important contributors in cell metabolism and division. ${ }^{93}$ Metabolic modifications are one of the most prolific characteristics of tumor/cancer cells. The ERRs in breast cancer modulate myriad cell metabolic pathways by regulating various oncoproteins and enzymes, including the Warburg effect (high rate of aerobic glycolysis), thereby facilitating increased cell growth and proliferation. ${ }^{94}$ Moreover, in thyroid tumors, the expression of ERR $\alpha$ inversely correlates with lactate dehydrogenase (LDH) $\mathrm{A}$ and $\mathrm{B}$ activities, which facilitate the metabolic adaptation of glycolysis. ${ }^{95}$ In thyroid tumors, ERR $\alpha$ expression is upregulated, thereby reprogramming the metabolic pathways by decreasing LDHA and LDHB activities, leading to preferential Warburg effect. ${ }^{95} \mathrm{~A}$ recent report by Bernatchez et al has demonstrated that silencing ERR $\alpha$ impairs colon cancer cell proliferation for in vitro and in vivo tumorigenesis. ${ }^{96}$ This is likely facilitated as a result of altered expression of several cell cycle regulators along with decreased expression of vital genes involved in metabolic pathways such as glycolysis, TCA cycle, and lipogenesis. Moreover, silencing of ERR $\alpha$ in colon cancer cells dramatically decreased glucose utilization, suggesting that ERR $\alpha$ positively influences colon cancer by controlling energy metabolism. ${ }^{96}$

The RORs have elaborate roles in metabolism, immunity, and in overall growth and development. Of late, data generated on RORs physiology from rodents have attributed them to diet-induced obesity and in the development of several obesity-related pathologies such as inflammation and insulin resistance, etc. ROR $\alpha^{\mathrm{sg} / \mathrm{sg}}$ mice (a natural mutant with ROR $\alpha$ deletion) when fed with a high-fat diet (HFD), exhibited lower body weight and lower fat content as compared to the wild type on a HFD, suggesting that ROR $\alpha$ may play a significant role in the onset and progression of obesity in humans. ${ }^{59}$ Moreover, reduced levels of ROR $\gamma$ in ROR $\alpha$-deficient mice also gives protection against diet-induced insulin resistance. Furthermore, ROR $\alpha^{\mathrm{sg} / \mathrm{sg}}$ mice exhibited a remarkable reduction in the expression of numerous genes involved in triglyceride biosynthesis and storage, immune response, TNF signaling, and proinflammatory roles, along with reduced inflammation of the WAT. ${ }^{97}$ These preliminary data indicate the regulatory role of ROR $\alpha$ in energy metabolism and immunity and suggest that it may positively contribute towards obesity and metabolic syndrome. In fact, ROR $\alpha$ is increasingly being seen as a potential target in the management of obesity and associated metabolic diseases.

\section{Epilogue}

Robust gene regulation is at the heart of every biological process. Transcriptional control is achieved by precise interaction of cell-specific regulatory proteins with the control regions associated with the genes. Notwithstanding the fact that several classes and types of transcription factors exist to control gene expression, the ONRs are a unique group of gene regulators whose ligands (or modulating signals) are currently unknown, and yet, they impinge upon a wide variety of biological processes in cells. A handful of receptors such as the PPARs, LXR, SXR, etc, were earlier considered a part of the ONR family; however, over time their ligands were identified and they were deorphanized. In spite of the unknown physiological ligands, we know substantial roles governed by the majority of the ONRs. A lack of or a very limited knowledge of the activation of ONRs is seen as a hindrance in revealing the signaling cascades governed by them. The coactivators are an integral component of the ONRs' control of gene expression, yet the crucial initial endogenous activating signal(s) of ONRs remains elusive. In the last decade, a number of PTMs of ONRs have been identified that possibly control differential receptor transactivation activities. However, the in vivo significance of PTMs of ONRs towards their control of gene expression activities is largely unknown. The biological functions governed by the ONRs are ever growing, and perhaps they participate in many physiological activities in vertebrates. However, we still only know a handful of their roles and probably the vast majority of their functions are unknown. Tissue-specific loss or gain of function approaches seems inevitable in order to 
reveal the specific roles played by the ONR members. With their wide spectra of roles, the ONRs are provided with the opportunity to participate in the onset and progression of various human diseases. Initial studies demonstrate links between the ONRs and some diseases such as cancer, obesity, dyslipidemia, and metabolic syndrome, etc. However, genetic evidence with respect to the involvement of the ONRs in these diseases is lacking. There has been a positive start on this and it is perhaps just a matter of time until some vital and convincing data will show the interplay between ONRs and human diseases. The ONRs field is continuously expanding and developing new opportunities. Increasing attention is being devoted to the myriad roles of ONRs in human diseases, while fundamental mechanisms of ONRs actions also remain the subject of investigation. With the explosion of information and detail now available from genome-wide studies, as well as in vivo real time studies, we are clearly at the defining moment in ONRs' biology.

\section{Acknowledgment}

The author expresses his gratitude towards St Edmund's College, Shillong for providing the research infrastructure.

\section{Disclosure}

The author reports no conflicts of interest in this work.

\section{References}

1. Lemon B, Tjian R. Orchestrated response: a symphony of transcription factors for gene control. Genes Dev. 2000;14(20):2551-2569.

2. Métivier R, Reid G, Gannon F. Transcription in four dimensions: nuclear receptor-directed initiation of gene expression. EMBO Rep. 2006;7(2):161-167.

3. Evans RM. The steroid and thyroid hormone receptor superfamily. Science. 1988;240(4854):889-895.

4. Beato M, Herrlich P, Schütz G. Steroid hormone receptors: many actors in search of a plot. Cell. 1995;83:851-857.

5. Lu NZ, Wardell SE, Burnstein KL, et al. International Union of Pharmacology. LXV. The pharmacology and classification of the nuclear receptor superfamily: glucocorticoid, mineralocorticoid, progesterone, and androgen receptors. Pharmacol Rev. 2006;58(4):782-797.

6. Moore DD, Kato S, Xie W, et al. International Union of Pharmacology. LXII. The NR1H and NR1I receptors: constitutive androstane receptor, pregnene $\mathrm{X}$ receptor, farnesoid $\mathrm{X}$ receptor alpha, farnesoid $\mathrm{X}$ receptor beta, liver $\mathrm{X}$ receptor alpha, liver $\mathrm{X}$ receptor beta, and vitamin $\mathrm{D}$ receptor. Pharmacol Rev. 2006;58(4):742-759.

7. Kliewer SA, Lehman JM, Wilson TM. Orphan nuclear receptors: shifting endocrinology into reverse. Science. 1999;284:757-760.

8. Benoit G, Cooney A, Giguere V, et al. International Union of Pharmacology. LXVI. Orphan nuclear receptors. Pharmacol Rev. 2006;58(4):798-836.

9. Giguere V. Orphan nuclear receptors: from gene to function. Endocr Rev. 1999;20:689-725.

10. Mangelsdorf DJ, Thummel C, Beato M, et al. The nuclear receptor superfamily: the second decade. Cell. 1995;83(6):835-839.

11. Chambon P. A decade of molecular biology of retinoic acid receptors. FASEB J. 1996;10(9):940-954.
12. Giguère V, Yang N, Segui P, Evans RM. Identification of a new class of steroid hormone receptors. Nature. 1988;331:91-94.

13. Becker-André M, André E, DeLamarter JF. Identification of nuclear receptor mRNAs by RT-PCR amplification of conserved zincfinger motif sequences. Biochem Biophys Res Commun. 1993;194(3): 1371-1379.

14. Robinson-Rechavi M, Laudet V. Bioinformatics of nuclear receptors. Methods Enzymol. 2003;364:95-118.

15. Blumberg B, Evans RM. Orphan nuclear receptors - new ligands and new possibilities. Genes Dev. 1998;12(20):3149-3155.

16. Willson TM, Brown PJ, Sternbach DD, Henke BR. The PPARs: from orphan receptors to drug discovery. J Med Chem. 2000;43:527-550.

17. Lengqvist J, Mata De Urquiza A, Bergman AC, et al. Polyunsaturated fatty acids including docosahexaenoic and arachidonic acid bind to the retinoid X receptor $\alpha$ ligand-binding domain. Mol Cell Proteomics. 2004;3:692-703.

18. Tzameli I, Pissios P, Schuetz EG, Moore DD. The xenobiotic compound 1,4-bis[2-(3,5-dichloropyridyloxy)]benzene is an agonist ligand for the nuclear receptor CAR. Mol Cell Biol. 2000;20:2951-2958.

19. Makishima M, Okamoto AY, Repa JJ, et al. Identification of a nuclear receptor for bile acids. Science (Wash DC). 1999;284:1362-1365.

20. Lehmann JM, McKee DD, Watson MA, Willson TM, Moore JT, Kliewer SA. The human orphan nuclear receptor PXR is activated by compounds that regulate CYP3A4 gene expression and cause drug interactions. J Clin Investig. 1998;102:1016-1023.

21. Burris TP, Guo W, McCabe ER. The gene responsible for adrenal hypoplasia congenita, DAX-1, encodes a nuclear hormone receptor that defines a new class within the superfamily. Recent Prog Horm Res. 1996;51:241-259.

22. Seol W, Choi HS, Moore DD. An orphan nuclear hormone receptor that lacks a DNA binding domain and heterodimerizes with other receptors. Science. 1996;272:1336-1339.

23. Sladek R, Bader JA, Giguere V. The orphan nuclear receptor estrogen-related receptor $\alpha$ is a transcriptional regulator of the human medium-chain acyl coenzyme A dehydrogenase gene. Mol Cell Biol. 1997; 17:5400-5409.

24. Ruse MD Jr, Privalsky ML, Sladek FM. Competitive cofactor recruitment by orphan receptor hepatocyte nuclear factor $4 \alpha 1$ : modulation by the F domain. Mol Cell Biol. 2002;22:1626-1638.

25. Perlmann T, Jansson L. A novel pathway for vitamin A signaling mediated by RXR heterodimerization with NGFI-B and NURR1. Genes Dev. 1995;9:769-782.

26. Gu P, Morgan DH, Sattar M, et al. Evolutionary trace-based peptides identify a novel asymmetric interaction that mediates oligomerization in nuclear receptors. $J$ Biol Chem. 2005;280:31818-31829.

27. Francis GA, Fayard E, Picard F, Auwerx J. Nuclear receptors and the control of metabolism. Аnпи Rev Physiol. 2003;65:261-311.

28. Aranda A, Pascual A. Nuclear hormone receptors and gene expression. Physiol Rev. 2001;81(3):1269-1304.

29. Giguere V. Transcriptional control of energy homeostasis by the estrogen-related receptors. Endocr Rev. 2008;29:677-696.

30. Ranhotra HS. The mammalian orphan nuclear receptors: orphans as cellular guardians. J Recept Signal Transduct Res. 2011;31(1):20-25.

31. Li Y, Choi M, Cavey G, et al. Crystallographic identification and functional characterization of phospholipids as ligands for the orphan nuclear receptor steroidogenic factor-1. Mol Cell. 2005;17: 491-502.

32. Nursa.org [homepage on the Internet]. The nuclear receptor signaling atlas; Tissue-specific expression patterns of nuclear receptors. Available from: http://www.nursa.org/datasets.cfm?doi=10.1621/datasets.02001. Accessed July 28, 2013.

33. Kumar R, Litwack G. Structural and functional relationships of the steroid hormone receptors' N-terminal transactivation domain. Steroids. 2009;74:877-883.

34. Chandra V, Huang P, Hamuro Y, et al. Structure of the intact PPARgamma-RXR-alpha nuclear receptor complex on DNA. Nature. 2008;456:350-356. 
35. Greschik H, Wurtz JM, Sanglier S, et al. Structural and functional evidence for ligand-independent transcriptional activation by the estrogen-related receptor 3. Mol Cell. 2002;9:303-313.

36. Flaig R, Greschik H, Peluso-Iltis C, Moras D. Structural basis for the cell-specific activities of the NGFI-B and the Nurr1 ligand-binding domain. J Biol Chem. 2005;280:19250-19258.

37. Lonard DM, O'Malley BW. Nuclear receptor coregulators: judges, juries, and executioners of cellular regulation. Mol Cell. 2007;27(5): 691-700.

38. Lonard DM, Lanz RB, O'Malley BW. Nuclear receptor coregulators and human disease. Endocr Rev. 2007;28(5):575-587.

39. Gaillard S, Dwyer MA, McDonnell DP. Definition of the molecular basis for estrogen receptor-related receptor alpha-cofactor interactions. Mol Endocrinol. 2007;21:62-76.

40. Berrabah W, Aumercier P, Lefebvre P, Staels B. Control of nuclear receptor activities in metabolism by post-translational modifications. FEBS Lett. 2011;585(11):1640-1650.

41. Anbalagan M, Huderson B, Murphy L, Rowan BG. Post-translational modifications of nuclear receptors and human disease. Nucl Recept Signal. 2012;10:e01.

42. Duplus E, Gras C, Soubeyre V, Vodjdani G, Lemaigre-Dubreuil Y, Brugg B. Phosphorylation and transcriptional activity regulation of retinoid-related orphan receptor alpha 1 by protein kinases $\mathrm{C}$. J Neurochem. 2008;104(5):1321-1332.

43. Han YH, Cao X, Lin B, et al. Regulation of Nur77 nuclear export by c-Jun N-terminal kinase and Akt. Oncogene. 2006;25(21):2974-2986.

44. Ranhotra HS. The estrogen-related receptor alpha: the oldest, yet an energetic orphan with robust biological functions. J Recept Signal Transduct Res. 2010;30(4):193-205.

45. Krzysik-Walker SM, González-Mariscal I, Scheibye-Knudsen M, Indig FE, Bernier M. The biarylpyrazole compound AM251 alters mitochondrial physiology via proteolytic degradation of ERR $\alpha . M o l$ Pharmacol. 2013;83(1):157-166.

46. Rana A, Rera M, Walker DW. Parkin overexpression during aging reduces proteotoxicity, alters mitochondrial dynamics, and extends lifespan. Proc Natl Acad Sci U S A. 2013;110(21):8638-8643.

47. Ren Y, Jiang H, Ma D, Nakaso K, Feng J. Parkin degrades estrogenrelated receptors to limit the expression of monoamine oxidases. Hum Mol Genet. 2011;20(6):1074-1083.

48. Xie S, Ni J, Lee YF, et al. Increased acetylation in the DNA-binding domain of TR4 nuclear receptor by the coregulator ARA55 leads to suppression of TR4 transactivation. J Biol Chem. 2011;286(24): 21129-21136

49. Lee MB, Lebedeva LA, Suzawa M, Wadekar SA, Desclozeaux M, Ingraham HA. The DEAD-box protein DP103 (Ddx20 or Gemin-3) represses orphan nuclear receptor activity via SUMO modification. Mol Cell Biol. 2005;25(5):1879-1890.

50. Yang FM, Pan CT, Tsai HM, Chiu TW, Wu ML, Hu MC. Liver receptor homolog-1 localization in the nuclear body is regulated by sumoylation and cAMP signaling in rat granulosa cells. FEBS $J$. 2009;276(2):425-436.

51. Auld KL, Berasi SP, Liu Y, et al. Estrogen-related receptor $\alpha$ regulates osteoblast differentiation via $\mathrm{Wnt} / \beta$-catenin signaling. $J \mathrm{Mol}$ Endocrinol. 2012;48(2):177-191.

52. Mirebeau-Prunier D, Le Pennec S, Jacques C, et al. Estrogen-related receptor alpha modulates lactate dehydrogenase activity in thyroid tumors. PLoS One. 2013;8(3):e58683.

53. Ramjiawan A, Bagchi RA, Albak L, Czubryt MP. Mechanism of cardiomyocyte PGC-1 $\alpha$ gene regulation by ERR $\alpha$. Biochem Cell Biol. 2013;91(5):148-154.

54. Kim DK, Ryu D, Koh M, et al. Orphan nuclear receptor estrogen-related receptor $\gamma(\mathrm{ERR} \gamma)$ is key regulator of hepatic gluconeogenesis. $J$ Biol Chem. 2012;287(26):21628-21639.

55. Fitzsimmons RL, Lau P, Muscat GE. Retinoid-related orphan receptor alpha and the regulation of lipid homeostasis. J Steroid Biochem Mol Biol. 2012;130(3-5):159-168.
56. Jetten AM. Retinoid-related orphan receptors (RORs): critical roles in development, immunity, circadian rhythm, and cellular metabolism. Nucl Recept Signal. 2009;7:e003.

57. Ranhotra HS. The interplay between retinoic acid receptor-related orphan receptors and human diseases. J Recept Signal Transduct Res. 2012;32(4):181-189.

58. Takeda Y, Jothi R, Birault V, Jetten AM. ROR $\gamma$ directly regulates the circadian expression of clock genes and downstream targets in vivo. Nucleic Acids Res. 2012;40(17):8519-8535.

59. Jetten AM, Kang HS, Takeda Y. Retinoic acid-related orphan receptors $\alpha$ and $\gamma$ : key regulators of lipid/glucose metabolism, inflammation, and insulin sensitivity. Front Endocrinol (Lausanne). 2013;4:1.

60. Mollema NJ, Yuan Y, Jelcick AS, et al. Nuclear receptor Rev-erb alpha (Nr1d1) functions in concert with $\mathrm{Nr} 2 \mathrm{e} 3$ to regulate transcriptional networks in the retina. PLoS One. 2011;6(3):e17494.

61. Cho H, Zhao X, Hatori M, et al. Regulation of circadian behaviour and metabolism by REV-ERB- $\alpha$ and REV-ERB- $\beta$. Nature. 2012;485(7396): 123-127.

62. Matsumura T, Imamichi Y, Mizutani T, et al. Human glutathione S-transferase A (GSTA) family genes are regulated by steroidogenic factor 1 (SF-1) and are involved in steroidogenesis. FASEB J. 2013;27(8): 3198-3208.

63. Kir S, Zhang Y, Gerard RD, Kliewer SA, Mangelsdorf DJ. Nuclear receptors HNF4 $\alpha$ and LRH-1 cooperate in regulating Cyp7a1 in vivo. J Biol Chem. 2012;287(49):41334-41341.

64. Chen HZ, Wen Q, Wang WJ, He JP, Wu Q. The orphan nuclear receptor TR3/Nur77 regulates ER stress and induces apoptosis via interaction with TRAP $\gamma$. Int J Biochem Cell Biol. 2013;45(8): 1600-1609.

65. Liu YY, Nakatani T, Kogai T, Mody K, Brent GA. Thyroid hormone and COUP-TF1 regulate kallikrein-binding protein (KBP) gene expression. Endocrinology. 2011;152(3):1143-1153.

66. Chen X, Qin J, Cheng CM, Tsai MJ, Tsai SY. COUP-TFII is a major regulator of cell cycle and Notch signaling pathways. Mol Endocrinol. 2012;26(8):1268-1277.

67. Boutant M, Ramos OH, Tourrel-Cuzin C, et al. COUP-TFII controls mouse pancreatic $\beta$-cell mass through GLP-1- $\beta$-catenin signaling pathways. PLoS One. 2012;7(1):e30847.

68. Ahn SW, Gang GT, Kim YD, et al. Insulin directly regulates steroidogenesis via induction of the orphan nuclear receptor DAX-1 in testicular Leydig cells. J Biol Chem. 2013;288(22):15937-15946.

69. El-Khairi R, Martinez-Aguayo A, Ferraz-de-Souza B, Lin L, Achermann JC. Role of DAX-1 (NR0B1) and steroidogenic factor-1 (NR5A1) in human adrenal function. Endocr Dev. 2011;20: $38-46$.

70. Yuk JM, Shin DM, Lee HM, et al. The orphan nuclear receptor SHP acts as a negative regulator in inflammatory signaling triggered by Toll-like receptors. Nat Immunol. 2011;12(8):742-751.

71. Yang CS, Yuk JM, Kim JJ, et al. Small heterodimer partner-targeting therapy inhibits systemic inflammatory responses through mitochondrial uncoupling protein 2. PLoS One. 2013;8(5):e63435.

72. Park YY, Kim K, Kim SB, et al. Reconstruction of nuclear receptor network reveals that NR2E3 is a novel upstream regulator of ESR1 in breast cancer. EMBO Mol Med. 2012;4(1):52-67.

73. Zou Y, Niu W, Qin S, Downes M, Burns DK, Zhang CL. The nuclear receptor TLX is required for gliomagenesis within the adult neurogenic niche. Mol Cell Biol. 2012;32(23):4811-4820.

74. Zeng ZJ, Johansson E, Hayashi A, et al. TLX controls angiogenesis through interaction with the von Hippel-Lindau protein. Biol Open. 2012;1(6):527-535.

75. Scheiermann C, Kunisaki Y, Frenette PS. Circadian control of the immune system. Nat Rev Immunol. 2013;13(3):190-198.

76. Inoue I, Shinoda Y, Ikeda M, et al. CLOCK/BMAL1 is involved in lipid metabolism via transactivation of the peroxisome proliferator-activated receptor (PPAR) response element. J Atheroscler Thromb. 2005;12(3): $169-174$. 
77. Guillaumond F, Dardente H, Giguere V, Cermakian N. Differential control of Bmall circadian transcription by REV-ERB and ROR nuclear receptors. J Biol Rhythms. 2005;20:391-403.

78. Dufour CR, Levasseur MP, Pham NH, et al. Genomic convergence among ERR $\alpha$, PROX1, and BMAL1 in the control of metabolic clock outputs. PLoS Genet. 2011;7(6):e1002143.

79. Giguère V, Dufour CR, Eichner LJ, Deblois G, Cermakian N. Estrogenrelated receptor $\alpha$, the molecular clock, and transcriptional control of metabolic outputs. Cold Spring Harb Symp Quant Biol. 2011;76: 57-61.

80. Burris TP. Nuclear hormone receptors for heme: REV-ERBalpha and REV-ERBbeta are ligand-regulated components of the mammalian clock. Mol Endocrinol. 2008;22(7):1509-1520.

81. Solt LA, Kojetin DJ, Burris TP. The REV-ERBs and RORs: molecular links between circadian rhythms and lipid homeostasis. Future Med Chem. 2011;3(5):623-638.

82. Stratmann M, Schibler U. REV-ERBs: more than the sum of the individual parts. Cell Metab. 2012;15(6):791-793.

83. Bugge A, Feng D, Everett LJ, et al. Rev-erb $\alpha$ and Rev-erb $\beta$ coordinately protect the circadian clock and normal metabolic function. Genes Dev. 2012;26(7):657-667.

84. Ranhotra HS. The estrogen-related receptors: orphans orchestrating myriad functions. J Recept Signal Transduct Res. 2012;32(2): 47-56.

85. Crumbley C, Wang Y, Kojetin DJ, Burris TP. Characterization of the core mammalian clock component, NPAS2, as a REV-ERBalpha/RORalpha target gene. J Biol Chem. 2010;285(46):35386-35392.

86. Poliandri AH, Gamsby JJ, Christian M, et al. Modulation of clock gene expression by the transcriptional coregulator receptor interacting protein 140 (RIP140). J Biol Rhythms. 2011;26(3):187-199.

87. Yang X, Downes M, Yu RT, et al. Nuclear receptor expression links the circadian clock to metabolism. Cell. 2006;126:801-810.
88. Teboul M, Gréchez-Cassiau A, Guillaumond F, Delaunay F. How nuclear receptors tell time. J Appl Physiol. 2009;107(6):1965-1971.

89. Zhao Y, Bruemmer D. NR4A Orphan nuclear receptors in cardiovascular biology. Drug Discov Today Dis Mech. 2009;6(1-4):e43-e48.

90. Bonta PI, van Tiel CM, Vos M, et al. Nuclear receptors Nur77, Nurr1, and NOR-1 expressed in atherosclerotic lesion macrophages reduce lipid loading and inflammatory responses. Arterioscler Thromb Vasc Biol. 2006;26(10):2288-2294.

91. Zhao Y, Howatt DA, Gizard F, et al. Deficiency of the NR4A orphan nuclear receptor NOR1 decreases monocyte adhesion and atherosclerosis. Circ Res. 2010;107(4):501-511.

92. Rius J, Martínez-González J, Crespo J, Badimon L. NOR-1 is involved in VEGF-induced endothelial cell growth. Atherosclerosis. 2006;184(2): 276-282.

93. Chang CY, McDonnell DP. Molecular pathways: the metabolic regulator estrogen-related receptor $\alpha$ as a therapeutic target in cancer. Clin Cancer Res. 2012;18(22):6089-6095.

94. Deblois G, Giguère V. Oestrogen-related receptors in breast cancer: control of cellular metabolism and beyond. Nat Rev Cancer. 2013;13(1) 27-36.

95. Mirebeau-Prunier D, Le Pennec S, Jacques C, et al. Estrogen-related receptor alpha modulates lactate dehydrogenase activity in thyroid tumors. PLoS One. 2013;8(3):e58683.

96. Bernatchez G, Giroux V, Lassalle T, Carpentier AC, Rivard N, Carrier JC ERR $\alpha$ metabolic nuclear receptor controls growth of colon cancer cells. Carcinogenesis. Epub June 29, 2013.

97. Kang HS, Okamoto K, Takeda Y, et al. Transcriptional profiling reveals a role for RORalpha in regulating gene expression in obesity-associated inflammation and hepatic steatosis. Physiol Genomics. 2011;43(13):818-828.
Journal of Receptor, Ligand and Channel Research

\section{Publish your work in this journal}

The Journal of Receptor, Ligand and Channel Research is an international, peer reviewed, open access, online journal. The journal welcomes laboratory and clinical findings in the fields of biological receptors, ligands, channel and signal transduction research including: receptors and signaling; ligands; transporters, pores and channels; binding and activation; receptor

\section{Dovepress}

regulation; role of receptors in diseases and their treatment; molecular basis of membrane structure and functions; molecular models of membranes. The manuscript management system is completely online and includes a very quick and fair peer-review system. Visit http://www.dovepress.com/ testimonials.php to read real quotes from published authors. 